\title{
LA GRAMÁTICA GNÓSTICA DE LA SALUD Y LA SANACIÓN EN LA RELIGIÓN AMERICANA. El CASO dE LA CIENCIA DE LA SALUd de MARY BAKER EdDY
}

\author{
The Healing Grammar Gnostic in the Posmodern American Religion. \\ Mary Baker Eddy's Christian Science of Health
}

Miguel Jesús Hernández-Madrid

Resumen: El artículo explora los alcances de un análisis relacional entre la gramática gnóstica contemporánea contenida en la religión estadounidense y las experiencias de sanación espiritual derivadas de ella. Se estudia el caso de la Ciencia Cristiana, fundada por Mary Baker Eddy en la segunda mitad del siglo XIX, con el propósito de reflexionar sobre la relevancia de esta experiencia en los escenarios de los campos religiosos contemporáneos.

Palabras clave: religión estadunidense, sanación, gnosticismo, Ciencia Cristiana.

Abstract: The article explores the extents of analysis between contemporary Gnostic grammar in the American religion and the spiritual healing experiences, by studying the Mary Baker Eddy's Christian Science, at XIX middle century. The purpose is to think about the importance of this experience in the world scenes of the contemporary religious fields.

Keywords: American Religion, Healing, Gnosticism, Christian Science.

\footnotetext{
Miguel Jesús Hernández Madrid es doctor en ciencias sociales con especialidad en antropología social por el Centro de Investigaciones y Estudios Superiores en Antropología Social-Occidente. Profesorinvestigador titular $\mathrm{C}$ en el Centro de Estudios Rurales de El Colegio de Michoacán, México. Temas de especialización: religión, cultura y sociedad en el occidente de México; cambio religioso y movilidades trashumantes; experiencias de sanación y espiritualidad en las sociedades contemporáneas de la era digital. Correo electrónico: miguelh@colmich.edu.mx.
}

Enviado a dictamen: 10 de junio de 2013. Aprobación: 12 de septiembre de 2013. Revisiones: 1. 


\section{Introducción}

$\mathrm{M}$ ax Weber, reconocido como uno de los fundadores de la sociología de la religión en Occidente, escribió en 1904 que el avance de la ciencia social no depende solamente de describir las relaciones de hecho entre cosas, sino de ponerlas en una perspectiva de relación conceptual entre problemas (Weber, 2001). Si consideramos este criterio para evaluar el equilibrio entre los conocimientos empíricos de una realidad y su discusión teórica, sobre todo cuando lo enfocamos en un campo especializado como los estudios del fenómeno religioso en las regiones centro y sur de América Latina, podremos apreciar algunos cabos sueltos que requieren atarse en los ámbitos de su complejidad histórica, social y cultural.

Desde la década de los ochenta del siglo XX, la antropología de la religión ha abierto varias líneas de investigación del fenómeno religioso en el sureste mexicano, Centroamérica, el Caribe y los países andinos, entre las que destacan la presencia y expansión del movimiento pentecostal, ${ }^{1}$ las formas culturales y étnicas del catolicismo popular, el impacto regional de la teología de la liberación pero, sobre todo, la relación social y política de estos movimientos con la movilidad territorial de grupos trashumantes y el peso de sus tradiciones y símbolos en la construcción de identidades en un mundo globalizado.

La amplia riqueza de las investigaciones realizadas en estas líneas ha ofrecido descripciones diversas sobre las maneras en que los actores se apropian y dotan de significado a la religión. No obstante, se puede apreciar grosso modo una tendencia que privilegia la descripción densa de los hechos y que incurre en la separación ficticia entre "práctica" y "teoría" que, o bien emula a la segunda como un marco interpretativo de los datos, o en su defecto la desplaza al terreno de la abstracción erudita. $^{2}$

Resulta paradójico que, habiendo tantos estudios sobre las religiones de cuño protestante y paraprotestante de origen norteamericano presentes en Centro y Sudamérica, no contemos con conceptos precisos para comprender lo que las diferencia en sus planteamientos teológicos y utópicos procedentes de una misma fuente: la Biblia, pero también de aquello que las hace variantes de experiencias que tienen conformaciones míticas y culturales comunes.

Cuando en una investigación antropológica o sociológica se dice que un converso - casi siempre socializado en la religión católica - adopta el credo de una religión pentecostal, de los testigos de Jehová, de los mormones o de los adventistas, iestamos considerando desde una perspectiva cognitiva que ese "converso" lidia con visiones religiosas del mundo y de lo sagrado tan distantes como el entusiasmo, el pragmatismo y el gnosticismo? También es frecuente "explicar" esta conversión arguyendo que es en la experiencia subjetiva del creyente donde tales visiones y creencias religiosas son apropiadas y transformadas, como si el sustrato ideológico de la religión adoptada fuera solamente un aditamento y no un dispositivo tecnológico para la conformación de sujetos. Surge entonces la pregunta: ¿cómo se va transformando un individuo en un creyente distinto al que era, cuando ejerce sobre sí mismo disciplinas sobre su mente-cuerpo, sobre sus preferencias y nociones habituales para alcanzar un estado óptimo de salvación y sanación espiritual?

Quedémonos con estas dos preguntas, de entre otras varias que se pueden formular, para mostrar que uno de los cabos sueltos en este tipo de investigaciones es "ese espacio" entre las experiencias del individuo y las doctrinas religiosas que dan forma a sus creencias y las ordenan en códigos traducibles en conductas (Foucault, 1983: 6). En la medida en que la noción de espacio es abstracta porque a lo más que podemos aspirar en su definición es a referirlo como un plano simbólico ordenador del sentido (Segato, 2007: 71), se nos plantea el reto de construir sus objetivaciones con nociones accesibles, siendo la de territorio la más común, pero no necesariamente la única.

Es mi propósito aquí argumentar que una vía para abordar ese espacio mediador entre la experiencia subjetiva y las formas de ser del orden es indagando cuáles son las gramáticas que estructuran el sentido de lo sagrado en sus formas religiosas, propensas a traducirse en técnicas y prácticas que el individuo 
ejerce sobre sí mismo. Esta mirada, que de entrada aceptamos que sigue varios de los planteamientos de Michel Foucault sobre los problemas del sujeto, el saber y las tecnologías del yo (Foucault, 1981, 1983, 1991), sugiere abrir la perspectiva inmediata de la investigación antropológica y sociológica dirigida a los hechos de corte etnográfico y descriptivo para enriquecerla con otras perspectivas transdisciplinares que articulan la especialidad de los estudios religiosos (Capps, 1995) con la crítica religiosa (James, 1994; Bloom, 1994), ambas modalidades desarrolladas en la academia estadounidense. La pertinencia de elegir estos enfoques es su objeto de estudio: la religión americana en la variedad de sus experiencias, que en su mayoría hace más de medio siglo que constituyen la fuerza de los movimientos religiosos en Centro y Sudamérica, al disputar la hegemonía del catolicismo en la "cura de los cuerpos y las almas" (Bourdieu, 1993: 103).

La premisa que se desprende de este planteamiento es que, mientras mejor conozcamos las gramáticas estructurantes de las religiones del cristianismo americano, estaremos en mejores condiciones de vincularlas con las experiencias de quienes hacen de su subjetividad un terreno de encuentro para dar sentido a sus creencias. En este artículo nos interesa tratar esta cuestión a través del fenómeno de la sanación en el marco de uno de los paradigmas religiosos del cristianismo americano que, si bien no es tan extenso ni impactante ni espectacular como el pentecostalismo, tiene un ingrediente clave para discutir la colocación en el mundo contemporáneo del creyente posmoderno, cada vez más individualista; nos referimos al paradigma de la Ciencia Cristiana y a su gramática gnóstica.

\section{La sanación religiosa del cuerpo y de las almas}

Si la definición de sanar es a primera vista muy elemental - el acto de recuperación de salud en un enfermo-, igual de sencillas son las de los medios para realizarlo, las concepciones de enfermedad y de salud, y lo que se logra o no sanar cuando se utilizan dispositivos médicos científicos, alternativos o de fe. Imposible establecer un consenso entre estos enfoques y prácticas. De ahí que para delimitar el tema de este trabajo recurramos a los criterios del método sociológico postulado por Emile Durkheim para definir las características del hecho social que será objeto de nuestras reflexiones.

Empecemos por ubicar la sanación en un campo religioso ${ }^{3}$ donde su realización es motivada y legitimada por la fe en doctrinas y disciplinas que los individuos adoptan para lograr un estado de salvación. El dominio judeocristiano de estas doctrinas y disciplinas sostiene una visión dualista sobre la enfermedad del cuerpo, cuya causa se halla en la condición humana del pecado original; en otras palabras, el ser humano está enfermo, no se pone enfermo, y su cuerpo es experimentado como un campo de batalla entre el bien y el mal, la carne y el espíritu. Finalmente, el creyente que, orientado por esta visión dualista, realiza sobre sí mismo un trabajo arduo y disciplinado de vigilia en el terreno de la experiencia personal, aspira a curar sus enfermedades mediante la sanación en la profundidad del alma, en la revelación del ser divino que habita en toda creatura a imagen y semejanza de Dios.

De ser correcta esta argumentación de los hechos, nos preguntamos: ¿de dónde provienen las concepciones que se objetivan en doctrinas y prácticas para motivar y convocar en su seguimiento la conversión de sujetos creyentes?

Para aportar algunas respuestas, a modo de hipótesis de trabajo, rastrearemos las configuraciones históricas y culturales de la gnosis una de las matrices donde se han generado saberes, prácticas y disciplinas de sanación en ámbitos poscristianos, pero no exclusivamente en ellos.

Debido a que este planteamiento requiere de un amplio espacio y tiempo de argumentación, centraremos nuestra exposición en examinar solamente una de las variedades de la religión estadunidense, cuya identidad poscristiana, siguiendo a Harold Bloom, justificaremos más adelante. Nuestra intención no es describir etnográficamente las situaciones empíricas en las que la gnosis se manifiesta en las prácticas de sanación, sino más bien proponer, a la luz de algunas experiencias de este tipo, un ejercicio sobre las relaciones conceptuales entre problemas que se anuncian en ellas. ${ }^{4}$ 
La exposición que sigue se organiza en cuatro secciones. Iniciamos caracterizando lo que se entenderá por religión estadounidense poscristiana. En seguida examinamos las conexiones entre el imaginario y la gramática gnóstica con la experiencia de sanación religiosa, para continuar el análisis con un estudio de caso: la Ciencia Cristiana de Mary Baker Eddy. Concluimos con algunas reflexiones sobre las proyecciones contemporáneas de la gnosis en el terreno religioso de la sanación.

\section{La religión estadounidense poscristiana}

Harold Bloom escribió un libro singular sobre la religión de su país que destaca por sus rasgos autóctono y nacionalista: La religión en los Estados Unidos. El surgimiento de la nación poscristiana (1994). ${ }^{5}$ Con base en su experiencia académica en el campo de la literatura, Bloom emprende una empresa paralela de crítica religiosa en la que reconoce dos precursores claves: William James, en el marco de la filosofía y la psicología pragmática, y el filósofo poeta Ralph Waldo Emerson, líder del movimiento trascendentalista de principios del siglo XIX.

La crítica severa de Bloom a la antropología y la sociología por sus limitaciones para comprender desde el fenómeno religioso el sentido imaginativo de sus gramáticas teológicas y prácticas, lo lleva a explorar otra vía de corte hermenéutico que examina las fuentes discursivas religiosas y las experiencias a ellas ligadas.

La tesis que estructura sus argumentos es que la religión estadounidense se configura por una ruptura crítica con los protestantismos históricos y denominaciones derivadas provenientes de Europa, especialmente el calvinismo. Se disfraza, escribe Bloom, de cristianismo protestante pero ha dejado de ser cristiana. Conserva la figura de un Jesús muy solitario y personal que es también la del Jesús resucitado, en vez del crucificado o el que ascendió de nuevo al Padre: "el Cristo estadunidense del siglo XX se ha convertido en una experiencia personal" (Bloom, 1994: 29). En esta tesitura es en la que Bloom conceptualiza la religión americanizada como poscristiana.
Como crítico de la religión encuentro dos características que están siempre presentes en todas las versiones auténticas de la religión estadunidense. El estadunidense encuentra a Dios en él mismo pero sólo después de encontrar la libertad para conocer a Dios al experimentar una soledad interna total. La libertad, en un sentido muy especial, es la preparación sin la cual Dios no se revela en la identidad propia del ser humano. Y esta libertad es en sí misma doble; la chispa o espíritu debe conocerse a sí misma para ser libre tanto de otras identidades propias como del mundo creado. Dios o Jesús encontrarán el espíritu porque existe algo en éste que ya es Dios o Jesús, pero lo divino ha de encontrar a cada espíritu sólo en el aislamiento total. La salvación, para el estadunidense, no puede venir por medio de la comunidad ni de la congregación, sino que es un acto de confrontación de uno a uno (Bloom, 1994: 30).

Contrario a lo que se interpreta, la religión estadounidense no es una intensidad restablecida del protestantismo histórico y dogmático. Como sugiere la cita anterior, se trata de otro producto que entrevera cuatro elementos idiosincráticos de la manera libre en la que se experimentan el temperamento y la espiritualidad:

De todas las extrañas sectas nativas de los Estados Unidos sólo cinco se han convertido en hilos indelebles de la religión estadunidense: los mormones, la Ciencia Cristiana, los Adventistas del Séptimo Día, los testigos de Jehová y los pentecostales. Su fuerte sobrevivencia, a pesar de sus sorprendentes doctrinas, se deriva esencialmente del núcleo oculto que contiene los elementos de la religión estadunidense: entusiasmo, orfismo, gnosticismo, milenarismo (Bloom, 1994: 29).

Cabe aclarar que el significado del término "secta" manejado por Bloom es muy cercano al concepto sociológico de Max Weber cuando, durante su viaje por Estados Unidos, describió las comunidades religiosas con las que tuvo contacto en función de su sentido y 
naturaleza. A diferencia de las definiciones que adjetivan la secta por su tamaño o desprendimiento de iglesias u organizaciones mayores, Weber enfatiza su rasgo ideal de "eclessia pura, de la comunidad visible de los santos", exclusiva en el conocimiento profundo de Dios, de cuyo seno son excluidos aquellos que ofenden su mirada (Weber, 2002: 932).

De los cuatro elementos que Bloom identifica como el núcleo duro de la religión americana —-mencionados al final de la última cita - examinaremos a continuación el rasgo gnóstico debido a que este elemento articula los demás.

\section{"Sabe más a gnosis que a gnosticismo". Gramáticas sincréticas en las concepciones religiosas de la sanación}

Los especialistas en el tema del gnosticismo tienen buen cuidado en señalar el significado original del concepto griego gnosis y diferenciarlo de las objetivaciones históricas que ha tenido al organizarse en movimientos y doctrinas religiosas o seudorreligiosas en la era cristiana (Guerra, 2005; Jonas, 2003; Rudolph, 2000). Harold Bloom, en su libro sobre la religión americana, utiliza indistintamente los términos de gnosticismo, visión gnóstica y gnosis para referirse a actitudes de interpretación, más que al conocimiento cabal de las doctrinas reconocidas como gnósticas, y a las consecuencias sincréticas de esta actitud, cuando se manifiesta entre los fundadores carismáticos de las sectas que integran la religión estadounidense para interpretar la Biblia y producir nuevas versiones doctrinarias que hacen referencia a esta fuente considerada como concluyente. Debido a la importancia de definir con precisión algunos matices de los términos que emplearemos en el análisis del tema de la sanación religiosa, dedicaremos los siguientes párrafos a comentar qué de la gnosis y del gnosticismo hay o no en la religión americana.

El punto de partida es entender que la palabra griega gnosis, cuya transliteración al español significa conocimiento, tiene una especial connotación en los textos gnósticos clásicos, diferente al conocimiento intelectivo, racional, sensorial, especulativo, pragmático u operativo, incluso diferente del específico de la fe. Gnosis es ante todo un conocimiento posible de tipo introspectivo psicológico-religioso, a veces con características místicas, superior a todos los demás porque en la propia interioridad del ser humano le permite encontrar respuestas a las preguntas: "ide dónde vengo? (del Pleroma), ¿dónde estoy? (aprisionado en lo corporal, material: el Kenoma), ¿a dónde voy? (al Pleroma)" (Guerra, 2005: 339). ${ }^{6}$ Hans Jonas completa el sentido de esta búsqueda en la transformación del "alma" al "espíritu" por la unión con una realidad considerada como "sujeto supremo" (Jonas, 2003: 69).

Es con base en esta definición como Bloom encuentra en la obra de William James (1994) una de las mejores y precursoras teorías de la religión americana que enlaza el espíritu de la gnosis helénica con el pragmatismo libre y solitario del estadounidense para buscar en la revelación interior respuestas a las mismas preguntas. Pero hay una gran distancia entre percibir la presencia de ciertas tendencias de la gnosis, referida en una experiencia compleja como la religión americana, e identificar en ella indicadores de lo que históricamente se ha configurado en movimientos y religiones gnósticas, con frecuencia reducidas al término gnosticismo, como si fuera un fenómeno de esencia invariable y continua.

Cuando Hans Jonas escribe sobre la religión gnóstica lo hace con una perspectiva histórica de larga, pero muy larga duración, en la que el término gnosis es utilizado en su significado conceptual de clase para aplicarse allí donde están presentes determinadas propiedades (Jonas, 2003: 66).

Quienes hayan trabajado metodológicamente con el concepto de larga duración de Fernand Braudel (1979) reconocerán la dificultad de ubicar cronológicamente la extensión y los momentos-circunstancias coyunturales en los que un proceso necesita proyectarse en el tiempo espacio para apreciar la magnitud y complejidad de su desarrollo. En el caso de la religión gnóstica, esta mirada tendría que remitirse a lo que varios historiadores reconocen, siguiendo a Karl Jaspers (1980), como el tiempo eje o era axial, ubicado tentativamente entre los años 700 y 200 a.e.c. 
El tiempo eje fue un parteaguas en la historia de la humanidad, resultado de miles de años de evolución económica y, por tanto, social y cultural, decisiva para el crecimiento espiritual de la humanidad. Este crecimiento se abocó a desarrollar la idea de una sola trascendencia universal, a cultivar una espiritualidad interiorizada y a destacar la importancia de la práctica de la compasión como la prueba auténtica de la religiosidad que tenía la capacidad de ver la santidad en todo ser humano (Armstrong, 2000: xii).

Durante la era axial aparecieron las grandes confesiones que han seguido guiando a los seres humanos en el mundo civilizado: el budismo y el hinduismo en la India; el confucianismo y el taoísmo, en Extremo Oriente; el monoteísmo, en Oriente Próximo, y el racionalismo en Europa (Armstrong, 2000: xii).

Pero también es necesario considerar, como la misma Karen Armstrong hace, que no todos los seres humanos experimentan de la misma manera ni se benefician por igual de los cambios tecnológicos y la modernidad. Gran parte de las reacciones religiosas contestatarias a estos procesos rechazan la materialidad y alienación provocadas por los placeres del consumo, de la artificialidad y del fetichismo que privan a los símbolos religiosos de su condición sagrada. ${ }^{7}$ Desde los tiempos antiguos hasta nuestra era posmoderna estas reacciones se expresan en fundamentalismos y en concepciones radicales que establecen rupturas entre el mundo material y la espiritualidad (Armstrong, 2000; Marty y Scott, 1991). En esta tesitura, Manuel Guerra encuentra en el gnosticismo antiguo, y en lo que de él pudiera estar presente en el moderno, estas reacciones de ruptura o polarización; no obstante, él mismo advierte sobre la necesidad de no sacar conclusiones precipitadas sobre su condición de fenómeno permanente o continuo en el tiempo, y de no confundir con las doctrinas gnósticas antiguas lo que no son actualmente sino coincidencias en temas, formas y apariencias (Guerra, 2005: 340).

Contextualizar la gnosis en la perspectiva de larga duración de la era axial nos invita a pensar de otro modo el problema que, con toda justificación, formula Manuel Guerra al comparar el gnosticismo antiguo con el moderno, en su amplia gama de sectas, iglesias y cofradías, y preguntarse: ison dos realidades entroncadas históricogenéticamente, una especie de caudal subterráneo que brota y rebrota o, por el contrario, se trata de formas con un parecido fenomenológico coincidente en unos cuantos temas? (Guerra, 2005: 340).

El punto de vista que sugerimos considerar, en la perspectiva de larga duración varias veces referida, es el de despejar la preocupación por explicar la gnosis en su condición de estructura significante y considerarla no como concepto, sino como condición de posibilidad -y de imposibilidad - de todos los conceptos y todas las palabras que sean significadas en experiencias.

Es éste el sentido de las gramáticas gnósticas al que nos referimos en el presente trabajo, como posibilidades de lenguajes de experiencias ${ }^{8}$ que, basadas en los tres principios señalados por Jonas — su naturaleza religiosa, salvífica y trascendente de dios-, son susceptibles de permear y de ser apropiadas en diversas confesiones religiosas o tradiciones espirituales que establecieron puentes místicos entre el cristianismo y el islam, por ejemplo, sin descartar a pensadores independientes. ${ }^{9}$ Es interesante mencionar que para Jonas el escenario histórico en donde ubica una de las manifestaciones más poderosas del gnosticismo antiguo es la Palestina de los tres primeros siglos de la era cristiana, caracterizado por numerosas sectas. Sobre ello escribe:

[...] la secta cristiana no fue más que un hecho aislado cuya respuesta escatológica ante la crisis espiritual de la época fue la creación de una mentalidad y práctica religiosa basada en la salvación, la trascendencia y la dualidad radical de los ámbitos del ser: Dios/mundo, espíritu/materia, cuerpo/alma, luz/oscuridad, bien/ mal, vida/muerte (Jonas, 2003: 66).

Continuemos nuestra exposición situándonos ahora en Lynn, Massachusetts, durante el último cuarto del siglo XIX, cuando la señora Mary Baker Eddy publicó en 1875 su tratado Ciencia y salud con clave de las Escrituras. 


\section{Gnosis y ciencia de la salud cristiana}

En esta sección pretendemos mostrar la presencia de una visión gnóstica religiosa en la doctrina de la Ciencia Cristiana original, postulada por la señora Mary Baker Eddy, con el fin de reflexionar sobre una de las propuestas metafísicas religiosas más interesantes que hace de la enfermedad y la sanación su campo de conversión y agencia.

Aun cuando la Iglesia del Cristo Científico fundada por Baker Eddy tuvo en su interior cismas que derivaron en un movimiento alternativo con diversas ramificaciones, que hoy en día se aprecian entre sus seguidores en varias partes del mundo (Melton, 2003), Ciencia y salud con clave de las Escrituras sigue reconociéndose como el texto fundamental. Con base en esta fuente, el ejercicio que haremos a continuación se organiza en dos movimientos: el primero examina la conexión entre creencia y saber para la formación de un sujeto sanador, tomando en cuenta el contexto biográfico e ideológico en el que se generó el saber religioso de una ciencia cristiana dirigida a curar el cuerpo y las almas; el segundo movimiento converge en el análisis de la objetivación gnóstica en la doctrina religiosa de Ciencia y salud.

Los investigadores que desde diferentes disciplinase interdisciplinas de los fenómenos religiosos pretendemos dar seguimiento a sus constantes transformaciones y explicar en sus delimitados perfiles sus causas y conexiones con otras dimensiones de la realidad, damos por sentado, con mucha frecuencia, el significado del término creencia como algo esencial, permanente, funcional y atributivo de los actores protagonistas de los procesos religiosos. Es en el momento de enfrentar el reto fenomenológico de entender en la perspectiva del Otro su sentido y experiencia de lo que para él significa creer, cuando nos percatamos de que la "creencia" es un modo de nombrar, como lo hizo Ortega y Gasset, "algo en lo que se está" (1976: 19), pero indisolublemente vinculado, en la era moderna y posmoderna según se vea, a los cantos de experiencia en sus múltiples variaciones. ${ }^{10}$

Por importante que sea el problema, no es el momento de abordar sus planteamientos epistémicos, pero sí de considerarlo para despejar en este universo una cuestión clave que se anuncia en el discurso religioso de la Ciencia Cristiana con respecto al poder de la sanación y su interiorización en el sanador; se trata de la relación entre creencia y saber. Quizás la manera pertinente de exponerla sea a través de un breve relato biográfico de la señora Baker Eddy.

Mary Baker Eddy nació en 1821 en Bow, New Hampshire, y falleció en 1910 en Boston. En esta región del noreste de Estados Unidos, conocida también como New England, se asentaron históricamente las iglesias de tradición congregacionalista, presbiteriana y puritanas consideradas baluartes conservadores de los protestantismos históricos provenientes de Europa (Carroll, 2000). Sus biógrafos coinciden en mostrar, desde la óptica estrictamente histórica (Gill, 1998; Gottschalk 2006) y desde la mirada del devoto (Caché y Towssend, 2003), que la atribulada vida de la señora Baker, en la que las enfermedades fueron constantes y severas al mantenerla en períodos largos de invalidez y convalecencia, además de los eventos traumáticos de su vida familiar, marital y ambiente social de su época, no fueron vividos con desdicha y pesar, sino como alicientes para fortalecer su fe. Fe no depositada en un credo o adscripción religiosa, sino en un compromiso y búsqueda personal de lo que para ella fue significando la revelación de Dios en sus experiencias de vida.

El constante diálogo que Mary Baker mantuvo con su cuerpo y mente en diferentes circunstancias marcadas por sus enfermedades a través de los ensayos de curación a los que recurrió para aplicarlos en sí misma y en otros, fue el derrotero y a su vez el contexto favorable para establecer una singular conexión entre saber y creencia.

Durante la mayor parte de su vida adulta, Mary había estado tratando de comprender la manera de sanar las dolencias físicas; no se conformaba con una mejoría, sino que anhelaba la curación completa. Con su estudio de homeopatía y los métodos que usaba Phineas Quimby para sanar por medio de la mente humana, ella se había convencido de que todas las dolencias son de naturaleza mental y de que su 
tratamiento depende completamente de la mente. Ahora, con la relación divina que había recibido en el momento de su propia curación espiritual, se le había demostrado que la única mente que se necesita para tratar la enfermedad debe ser la Mente divina, Dios, y no otra. Y lo que hacía que la curación divina fuera superior a todos los demás métodos, era que no sólo sanaba la enfermedad, sino que inevitablemente también hacia que el paciente mejorara moralmente (Caché y Towsend, 2003: 46-47).

Harold Bloom y Gillian Gill destacan la contundente influencia que el sanador Phineas Quimby tuvo en una coyuntura vital de la señora Mary (1862-1864), en el tratamiento de sus enfermedades físicas y psíquicas por medios mentales que incluían el hipnotismo, tan en boga en esa época por los seguidores de Friedrich Mesmer, inventor de la teoría del magnetismo animal benéfico y malévolo. Mary Baker, más que adoptar el método del doctor Quimby lo puso a prueba en pacientes, a veces en el mismo médico sin que él lo supiera. En una ocasión, narra Mary Baker con detalle, una paciente que sufría hidropesía había sido desahuciada por su médico y ella tomó el caso administrándole los mismos medicamentos y dosis. El resultado fue una mejoría considerable de la paciente. Entonces, Mary Baker sustituyó los medicamentos por placebos acompañados de sus oraciones y los resultados fueron igual de gratificantes hasta que sanó completamente. Ante esta experiencia, la señora Mary escribió: “[...] para mí fue como la caída de la manzana: me mostró claramente que la mente gobernaba todo lo relacionado con su recuperación" (Caché y Towsend, 2003: 23). Pero la caída de la manzana a la que Mary Baker alude, en referencia a la anécdota de Newton, es la de una "iluminación acerca de la comprensión humana" que no es la de la mente física, sino "la revelación de la Mente divina". En sus propios términos esto significa que, ante el hecho de que tanto el pensamiento de la paciente como el pensamiento del médico se enfocan en la causa material de la enfermedad, no hay posibilidad de curación. En conclusión:
El médico tiene que conocerse a sí mismo y entender el estado mental de su paciente... "Saca primero la viga de tu propio ojo". Entérate de lo que en tu propia mentalidad es desemejante al "ungido" y échalo fuera; entonces discernirás el error en la mente de tu paciente que hace que su cuerpo esté enfermo y sacarás ese error y descansarás como la paloma del diluvio (Caché y Towsend, 2003: 25).

Con "la caída de la manzana", la señora Mary dejó atrás los métodos materiales al comprobar que nada tenían que ver con el proceso sanador; pero hubo otra "caída" literal y no metafórica que sufrió en 1866 al resbalar en el hielo en Lynn y que la mantuvo inválida algún tiempo. Este hecho convertido en mítico entre los seguidores de la Ciencia Cristiana marca la frontera entre la anterior experiencia física y material de la sanación y la revelación del camino de la Mente divina. Sus biógrafos devotos narran que en su convalecencia la señora Mary prometió a Dios que, si le devolvía la salud, "dedicaría el resto de su vida a ayudar a la enferma y sufriente humanidad". Fue entonces cuando intensificó su estudio de la Biblia ${ }^{11}$ y comenzó la redacción de Ciencia y salud, pero también cuando comprobó que, por medio de la oración interior y de la lectura de la Biblia, el poder sanador divino hacía efecto, saber del que ella misma fue el primer testimonio cuando por su propio pie se levantó del lecho en el que los médicos habían diagnosticado que permanecería con poco tiempo de vida. ${ }^{12}$

La lectura gnóstica que Mary Baker realiza, sin percatarse y mucho menos identificarse con una doctrina de tal denominación, estriba en el itinerario que se inicia con su fe en la calidad divina de la Biblia, con base en la cual comprende el sentido de un hecho o de un acto como la enfermedad. Al darse cuenta de sus implicaciones e importancia, problematiza las razones que la justifican en el plano de la realidad material, corporal y mental para desplazarse a una experiencia de sanación en el terreno del saber. Como ya se ha dicho, este saber equivalente a gnosis - conocimiento - no está en la dimensión de la introspección racional — según el modelo cartesiano-, sino en otro tipo de introspección proporcionado por la revelación religiosa en la experiencia. 
Mary Baker no puso a prueba su fe en el terreno de la experimentación empírica, sino que con la mirada de su fe reflexionó las experiencias de sanación en el campo de los saberes médicos de su época y problematizó su efectividad al comparar los resultados alternativos que ofrece la revelación de otro tipo de conocimiento en la dimensión que considera divina. Este proceso que podríamos representar del saber a la creencia creencia en la que Mary Baker siempre estuvo "suelta"nos invita a retomar lo que Luis Villoro propone al escribir que los grados de la creencia no corresponden con intensidades crecientes en los sentimientos de convicción, sino con grados en la probabilidad que se atribuye a la proposición creída: "Para creer es indispensable percatarse de lo que se cree, lo cual puede en muchos casos, expresarse con este sentido de saber" (Villoro, 2000: 129).

El Cristo Jesús científico que Mary Baker perfila en su iglesia no tiene ningún antecedente en los tratados teológicos cristológicos de las religiones protestantes y católica, ${ }^{13}$ pero tampoco es objeto de interés en Cienciay salud, ni al parecer en otros de sus escritos, el justificar la identidad divina de Cristo; simplemente se asume que sus poderes curativos no provienen de un avatar que lo encarna, sino de la manifestación de la Mente divina que por un misterio amoroso muestra el camino de la sanación. Bloom afirma en su lectura crítica de la obra de la señora Mary Baker que lo único que se anuncia en ella sobre dios es una noción, en sentido literal, que evoca la imagen del dios extraño de los gnósticos: impersonal, inactivo, que no es responsable del mal ni hacedor de la materia, del mundo, que es el mal. ¿Estaremos de acuerdo con esta interpretación de Bloom al leer el siguiente pasaje de Ciencia y salud?

¿Somos irreverentes para con el pecado, o estamos atribuyendo demasiado poder a Dios, cuando atribuimos a Dios Viday Amor todopoderosos? Niego que Él coopere con el mal, porque deseo no tener fe en el mal o en cualquier poder, excepto Dios, el bien (Baker, 1995: 348).

Si a partir de esta noción hay una lógica conectiva con Cristo, ésta no es la aceptación de que Dios pueda ser un hombre dotado de cuerpo material, sino más bien que el Jesús histórico de Nazareth se configura en Cristo porque sobre él desciende el pleroma durante su bautizo en el Jordán. El cuerpo es tan sólo un receptáculo y la redención no ocurre entonces por la pasión y muerte de los pecados, sino por la gnosis (Guerra, 2005: 341).

Esta visión sobre la naturaleza divina de Cristo es la llave para entender la definición de enfermedad y sanación y el método científico de curación en la propuesta religiosa de Mary Baker que resumimos en los siguientes puntos.

- La enfermedad no está definida como un concepto, sino como un fenómeno compartido con el pecado y la muerte que son parte de la naturaleza humana. Su poderosa presencia estriba en las maneras que la mente humana material hace de ellas realidades que no tienen existencia propia.

- Es por ello que no habrá ninguna sanación mientras se intente curar la enfermedad con métodos basados en la fe humana en la materia, y no en el tipo de ciencia que tiene fe en la acción de la mente carnal (Baker, 1995: xi). Al respecto

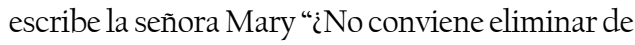
la llamada mente mortal aquello que, mientras permanezca en ella, se manifestará en formas de pecado, enfermedad y muerte? En lugar de defender tenazmente los supuestos derechos de la enfermedad, mientras nos quejamos del sufrimiento que la enfermedad trae ino convendría abandonar esa defensa, especialmente cuando al hacerlo puede mejorarse nuestra situación y la de otras personas también?" (Baker, 1995: 348).

- La Ciencia Cristiana sana con la oración Divina. "La oración más elevada no es simplemente una oración de fe; es demostración. Tal oración sana la enfermedad y debe destruir el pecado y la muerte" (Baker, 1995: 16).

- La señora Mary Baker enfatiza constantemente en Ciencia y salud la diferencia entre la oración de la mente humana y de la mente divina. La oración sanadora no es un mero ruego de que Dios sane al enfermo. "El efecto beneficioso de tal oración 
por el enfermo se produce en la mente humana haciéndola obrar más poderosamente sobre el cuerpo por medio de una fe ciega en Dios [...] Al orar a un Dios corpóreo afecta al enfermo como un medicamento, el cual no tiene eficacia propia sino que deriva su poder de la fe y la creencia humanas. El medicamento no surte efecto de por sí, porque carece de inteligencia". A diferencia de esta manera de oración "En la Ciencia divina, donde las oraciones son mentales, todos pueden contar con Dios como pronto auxilio en las tribulaciones" (Baker, 1995: 13).

- La oración mental, en silencio y recogimiento interior, evita el mundo de lo sensorio y todo aquello que la pueda distraer, porque "la vida está en el Alma y no en el cuerpo" (Baker, 1995: 13).

- El sanador de la Ciencia Cristiana no es el que hace de la oración un método sino un camino de encuentro interior que comparte amorosamente con otros. "La capacidad de sanar como lo hizo Jesús, de forma rápida y completa, sólo por medio de la oración, es resultado de una vida cimentada en el Cristo: un pensamiento puro y amoroso que comprende correctamente y confía plenamente en que Dios es el Padre-Madre divino que se ocupa por completo de todas Sus creaturas en toda $\mathrm{Su}$ creación" (Caché y Towsend, 2003: xvii).

La crítica religiosa emprendida por Bloom al centrarse en el análisis del sentido teológico —en parte poético diría él-y del discurso de las variedades religiosas americanas tiende a distraer el peso de la dimensión de la experiencia, tan importante para William James. Con esta observación nos interesa atender dos aspectos de la propuesta religiosa de sanación que hemos resumido antes.

El primero es la importancia de la experiencia, entendida como un estado continuo de desarrollo en la práctica de la oración mental divina interior y el sostenimiento de las condiciones que la favorecen en la vida cotidiana. La revelación nunca es entendida en este contexto como una "chispa" que el individuo recibe en su subjetividad, sino como un encuentro construido en un proceso de búsqueda y comprensión de las limitaciones del cuerpo físico. En este sentido, el análisis de la conversión como proceso posible si se dan las condiciones subconscientes activas adecuadas, realizado por William James, es pertinente para reflexionar la propuesta de la Ciencia Cristiana, en la que Mary Baker Eddy es muy clara al escribir en diversas partes de Cienciay salud acerca de la ilusión de creer que, por tan sólo pedir a Dios que se quiere mejorar y ser amado por Él, se logra tal anhelo.

El anhelo de ser mejores y más santos, expresado en vigilancia diaria y en el esfuerzo por asimilar más del carácter divino, nos modelará y formará de nuevo, hasta que despertemos a Su semejanza. Alcanzamos la Ciencia del cristianismo demostrando la naturaleza divina, pero en este mundo malvado será "vituperado vuestro bien", y la paciencia tiene que traer experiencia (Baker, 1995: 4).

El segundo aspecto requiere considerar algunos matices del significado de ciencia. La raíz etimológica latina de ciencia, scientia: conocimiento, deriva del participio activo de scire: saber, y por lo tanto el conocimiento significa el saber con consciencia (Corominas 1998: 149). Me parece interesante tomar en cuenta esta acepción de conocimiento junto con la de gnosis, de origen griego, porque articulan el sentido del sanador de la Ciencia Cristiana como sujeto que interioriza en su experiencia una disciplina ascética de conducta recta porque es la única manera de ejercer su ministerio y comprobar la efectividad de la curación profunda revelada por la mente divina. En esta perspectiva pragmática donde la conducta científica basada en el saber se realiza en la gnosis de la revelación divina, no hay cabida para el parloteo mecánico de la oración en el terreno de los sentidos, tampoco para la ilusión imaginada de la revelación por el solo hecho de pensarla y desearla, ni para la tentación de reducir el amor a un sentimiento o emoción. Esta manera de entender y realizar en la praxis la Ciencia Cristiana está más cerca de las experiencias de los primeros cristianos que experimentaron la filocalia: la oración de Jesús, ${ }^{14}$ aunque no de sus planteamientos 
doctrinarios, entendida como la búsqueda de la consciencia, profunda y beatificante, de la vida divina ya presente y operante en los bautizados (Filocalia, 1982: 24).

\section{Reflexiones recapitulares}

El riesgo de pretender mostrar en un artículo lo forjado en el terreno de la experiencia es el de estriar en un discurso lógico inferencial, formateado por los datos y las cifras, aquello que requiere de una gramática novedosa y articuladora de las dimensiones subjetiva, racional, intuitiva y ética como lo sugiere el sociólogo Danilo Martuccelli (2007). Es por ello que proponemos a modo de recapitulación algunas pistas para relacionar la experiencia de sanación religiosa abordada con otras experiencias. Sugerimos tener presente la imagen de las ondas que se extienden en la superficie de un ojo de agua cuando una piedra impacta sobre ella, creando el efecto de dimensiones espirales, aparentemente conectadas pero contingentes en su duración.

Una de estas ondas que hemos tratado de seguir sistemáticamente es la propuesta de Bloom sobre los núcleos duros estructuradores de la religión americana, de los cuales la visión gnóstica ha tenido un papel fundamental, y la variedad de la experiencia de la iglesia de la Ciencia Cristiana representa una de sus expresiones más acabada. La perspectiva de Bloom, siguiendo a William James y Ralph Waldo Emerson, consiste en colocar la mirada en los cantos de experiencia porque permite apreciar la lectura del paisaje religioso en los matices de sus prácticas y sentidos convocantes, sin dejar por ello de reconocer sus rivalidades doctrinarias y las competencias por las almas y los cuerpos en un campo religioso.

Esta otra mirada nos parece pertinente para explorar el fenómeno de la sanación religiosa porque a la luz de la Ciencia Cristiana nos admiramos de otras experiencias como la de la sanación pentecostal, en la que el "entusiasmo" y no la gnosis proponen un camino diferente en la concepción del cuerpo, la enfermedad y la curación física y del alma, incluso a través de la oración carismática concebida de manera diferente a la de la mental divina (Csordas, 1997).
El contexto social y cultural es otra dimensión a considerar en la comprensión de lo que significa como hecho histórico la religión americana y sus consecuentes propuestas sobre la sanación. Harold Bloom ubica en Cane Ridge, Kentucky, el origen de la religión americana durante la masiva asamblea que en 1801 reunió durante una semana a integrantes de diferentes iglesias sureñas, de composición social y racial mayoritaria de las clases rurales pobres (Bloom, 1994: 60). Este awakening es una alegoría del mito fundante pentecostés que convoca al descubrimiento del sentido religioso en el interior del individuo, desplazando la ubicación de su legitimidad en la pertenencia y adscripción a un credo y doctrina. Es por ello que para Bloom este acontecimiento significa el descubrimiento del creyente que encuentra a Dios y a Jesús en su interior personal y solitario, aun cuando este encuentro requiera de la afirmación de ese saber en el marco comunitario.

La pista a seguir para evitar convertir la mirada del contexto histórico social y cultural en un lugar común son las relaciones de poder y control en la vida cotidiana y de las reacciones que ante éstas produjeron la emergencia de nuevos agentes religiosos. Caché y Towsend comentan que, aunque Mary Baker Eddy no era por su posición social una esclava, en un lugar y tiempo donde el esclavismo era el régimen social y económico dominante a finales de 1854, antes de enviudar de Daniels Patterson: "conocía muy bien la esclavitud. Para ella, también era esclavitud un cuerpo material atado por las cadenas de la enfermedad crónica, bajo el látigo del dolor" (Caché y Towssend, 2003: 29). A este comentario podríamos agregar, siguiendo los datos biográficos de Gill, que también padeció la esclavitud del sistema conservador patriarcal de su época en el que como mujer no tuvo el derecho de conservar a su hijo del primer matrimonio, fue engañada y abandonada por su segundo marido y criticada constantemente por los pastores de su iglesia cuando comenzó a practicar su método de sanación.

Al concluir la redacción de este artículo la página web del órgano oficial de la Ciencia Cristiana ${ }^{15}$ indica seguidores en 135 países de Europa y América Latina, así como en Canadá y los Estados Unidos. Aun 
cuando tiene una iglesia sede, la Iglesia Madre del Cristo Científico en Boston, Massachusetts, el fuerte de su organización radica en las alrededor de dos mil salas de lectura para el estudio de las Escrituras bajo la dirección del texto fundador de Mary Baker Eddy Ciencia y salud, los programas de radio en diversos idiomas, sintonizables en su página web, y todo el material escrito relacionado con el tema que también se consulta y es accesible en formatos digitales. Lo más cercano a los templos y congregaciones que caracteriza a otras religiones cristianas son los grupos de testimonio coordinados por maestros, sanadores y enfermeros acreditados por la Iglesia del Cristo Científico. Estamos ante una religión que hace de la tecnología virtual e informática el medio para convocar seguidores, establecer redes sociales y difundir información. En 2003 la traducción al español de la biografía de Mary Baker Eddy autorizada por la Iglesia de la Ciencia Cristiana (Caché y Towsend, 2003) fue presentada en diversas ferias del libro realizadas en México, Chile, Colombia, Cuba y Venezuela. El interés por la vida y el mensaje de la autora de Ciencia y salud con clave de las Escrituras se manifiesta en grupos urbanos de intelectuales, seguidores de las versiones contemporáneas de la metafísica gnóstica y el misticismo cuántico, pero también se detecta en grupos de mujeres que reivindican el feminismo precursor de la señora Baker Eddy en el campo de la sanación. He aquí un tema de investigación importante para las ciencias sociales.

Otra onda en expansión que repercute más allá del contexto histórico de la religión americana, si lo enfocamos en una perspectiva de larga duración, es el fenómeno de individuos que ensayan, en el terreno de la experiencia, la posibilidad de su subjetividad como proyecto de vida o como adscripción a un proyecto religioso ya dado en el que se construyen como sujetos. Es la tendencia de larga duración de la era axial que en el mundo moderno se objetiva en un dilema de doble batiente. Por un lado, parece indicar la ruptura del individuo con las visiones religiosas cristianas y seculares racionales que hacen del cuerpo y el espíritu una dicotomía irresoluble. Emmanuel Levinas identifica precisamente en la experiencia del dolor, en el seno mismo del sufrimiento corporal, la posibilidad de una rebelión, un rechazo a esa oposición entre cuerpo y espíritu, para superar esa concepción del cuerpo como accidente o prisión del alma (Levinas, 1998: 48). Pero la otra batiente parece contradecir esta conquista sobre el dualismo de la carne y el espíritu, al observarse en las versiones gnósticas posmodernas un retorno de la búsqueda espiritual en un ser interno despojado de su cuerpo, o bien en el que el cuerpo es tan sólo un campo de batalla para la superación de la enfermedad y el sufrimiento.

Abordar este dilema por el camino de los cantos de experiencia nos aboca a no conformarnos con ubicar a los sujetos en sus roles de consumidores de bienes de salvación, sino a descubrir si el fuerte peso de lo que implica realizar este tipo de experiencia no es acaso un reto insoluble para los seres humanos de una era digital que hace del sufrimiento, la enfermedad y la muerte una presentación ilusoria en sus datos y en las maneras mágicas de resolverlas (Kaminer, 2001).

¿Cómo y dónde se construyen no los sujetos colonizados, sino los que hacen de su libertad individual una vía para deconstruirse como sujetos? No es la presencia del dilema, sino la posibilidad de plantear en el contexto de éste la pregunta anterior, lo que nos sigue abriendo posibilidades de asombro ante la complejidad y riqueza de los fenómenos religiosos y de descubrirlos, como escribió Proust, no yendo a nuevos mundos, sino mirando y recorriendo los que habitamos de otras maneras.

\section{Notas}

${ }^{1}$ A manera de ejemplo citamos el proyecto pionero de investigación sobre la diversidad religiosa en el sureste de México coordinado por el CIESAS-Sureste a mediados de la década de los ochenta (CIESAS sureste, 1988, 1989); para el caso de Centroamérica, tomemos en cuenta la primera antología que enfoca el pentecostalismo como movimiento religioso de alcance amplio: Algo más que opio (Boudewijnse, Droogers y Kamsteeg, 1991), así como la investigación de Manuela 
Cantón en Guatemala (1998) que vincula los procesos de conversión religiosa a religiones protestantes con la guerra civil y la persecución militar en ese país; para el caso de los estudios andinos, son representativos los trabajos pioneros de Manuel M. Marzal en las sociedades campesinas, una de las primeras investigaciones que vinculó la emigración de campesinos a las urbes con su conversión a religiones evangélicas (Marzal, 1986, 1988).

2 Una excepción de consideración necesaria es el tratado de antropología religiosa de América Latina de Manuel M. Marzal (2002), que pone en la perspectiva de la reflexión conceptual la amplia experiencia histórica y etnográfica de los estudios religiosos, explorando otros enfoques epistemológicos para puntualizar los "cabos sueltos" referidos en el primer párrafo.

3 Retomamos el sentido teórico y metodológico del concepto "campo religioso" desarrollado por Bourdieu para construir objetos de estudio en los que se dé cuenta de las relaciones sociales y religiosas entre agentes que compiten, como lo propusiera Max Weber, por la cura de los cuerpos y de las almas (Bourdieu, 2006, 1993).

${ }^{4}$ Este ejercicio de rastreo de los dominios de saberes que perfilan la formación de sujetos sociales y la producción de enunciados se sustenta en la lectura y discusión de La arqueología del saber de Michel Foucault, a partir de lo cual realizamos un ensayo anterior (Hernández, 2007).

${ }^{5}$ La primera edición en inglés del libro fue en 1992. En 2006 Bloom vuelve a publicar otra edición corregida y aumentada (Bloom, 2009).

${ }^{6}$ El gnosticismo antiguo define el pleroma como el ámbito de la plenitud, de lo totalmente lleno por Dios; en contrapartida, el kenoma es el ámbito del vacío, de la nada. Es en este segundo en donde se ubican la materia, las cosas, el universo con todo lo que contiene. En esta cosmogonía, los hombres no son redimidos por una pasión y muerte expiatoria de los pecados, sino por la gnosis. Es ésta la que, al alcanzar un grado de espiritualidad por encima de la materia, garantiza el retorno al pleroma divino (Guerra, 2005: 340-341).

${ }^{7}$ Al respecto se recomienda consultar el librode José María Mardones, La vida del símbolo (2003), donde analiza con profunda singularidad el problema de la pérdida y la disolución de los referentes que dan sentido al símbolo religioso en nuestra época, y el de las posibilidades para recuperar esta importante dimensión.

${ }^{8}$ La argumentación de esta propuesta, que tiene de fondo una postura epistemológica razonada desde la fenomenología deconstructiva de Jacques Derrida (Yébenes, 2008) y la sociología reflexiva de Lucien Goldmann $(1972,1985)$, exige otro espacio y momento para su exposición. No obstante, nos atrevemos a afirmar que esta mirada de la cuestión problematiza las concepciones deterministas de las estructuras y proyecta en procesos reflexivos e históricos las transformaciones y posibilidades de articulación que una visión de mundo, como el gnosticismo por ejemplo, podría tener en perspectivas de larga, mediana y corta duración.

${ }^{9}$ En efecto, se identifican otras variaciones gnósticas no familiares en Occidente, pero sin duda relevantes para Oriente Próximo y Oriente Medio, como el sufismo, que han salido a la luz a partir de investigaciones recientes que rescatan y publican textos importantes de sus doctrinas (López-Baralt, 1999); y ni qué decir de la obra de Miguel Asín Palacios, dedicada a fundamentar las conexiones entre el islam y el cristianismo en el contexto de la movilidad que favoreció el período $\mathrm{Al}$ Ándalus, cuyos máximos exponentes en el mundo cristiano occidental fueron Santa Teresa de Jesús y San Juan de la Cruz (Asín, 1981).

10 Retomamos de Martín Jay (2009) su poética y pertinente sugerencia inspirada en Walt Whitman de enunciar el complejo tema universal y polifónico de la experiencia en términos de cantos, para tratar sus matices discursivos en sus sentidos epistemológicos. ¿Podrá hacerse algo similar algún día para abordar el tema de la creencia?

${ }^{11}$ En la edición en español de Ciencia y salud consultada hay un dato importante que conviene considerar con respecto a la versión de la Biblia sobre la que Mary Baker Eddy trabajó: la autorizada de King James [1611]. La traducción de la Biblia al español que la Ciencia Cristiana utiliza como fuente es la de Cipriano de Valera [1602].

${ }^{12}$ Véase el interesante y emotivo relato que de este episodio hacen Caché y Towsend a partir de la narración de Mary Baker Eddy (Caché y Towsend, 2003: 38-41). 
${ }^{13}$ Leonardo Boff, en el capítulo uno de su libro Jesucristo el liberador (1994), proporciona un estado de la cuestión actualizado sobre los enfoques cristológicos que en las teologías de las religiones cristianas han abordado la cuestión de quién es Cristo desde la perspectiva de la historia y de la fe.

${ }^{14}$ La oración de Jesús es la invocación del Señor Jesús, constantemente repetida con los labios, con la mente y con el corazón, solamente poniendo en ello el intelecto, silenciosamente entregado (Filocalia, 1982: 38).

${ }^{15}$ Página oficial en español de la Iglesia de la Ciencia Cristiana: http://cienciacristiana.org/ [consultada 5 de mayo de 2013].

\section{Referencias bibliográficas}

Armstrong, Karen, (1996) Jerusalem. One City,Three Faiths. Nueva York, Alfred Knopf.

Armstrong, Karen, (2000) The Battle for God. Nueva York, Alfred Knopf.

Asín Palacios, Miguel, (1981) El islam cristianizado. Estudio del sufismo a través de las obras de Abenarabi de Murcia. Madrid, Hiperión.

Baker Eddy, Mary, (1995) Ciencia y salud con clave de las Escrituras. Boston, The Writtings of Mary Baker Eddy. Bloom, Harold, (1994) La religión en los Estados Unidos. El surgimiento de la nación poscristiana. México, Fondo de Cultura Económica.

Bloom, Harold, (1997) Presagios del milenio. La gnosis de los ángeles, el milenio y la resurrección. Barcelona, Anagrama.

Bloom, Harold, (2009) La religión americana. México, Taurus.

Boff, Leonardo, (1994) Jesucristo el liberador. Ensayos de cristología crítica para nuestro tiempo. Bilbao, Sal Terrae.

Boudewijnse, Bárbara, André Droogers y Frans Kamsteeg (eds.), (1991) Algo más que opio. Una lectura antropológica del pentecostalismo latinoamericano y el caribeño. Costa Rica, Departamento Ecuménico de Investigaciones.

Bourdieu, Pierre, (1993) “La disolución de lo religioso" en Cosas dichas. Barcelona, Gedisa, pp. 102-110.

Bourdieu, Pierre, (2006) "Génesis y estructura del campo religioso" en Relaciones. Estudios de historia y sociedad.
Vol. XXVII, núm. 108, otoño. Zamora, Michoacán, El Colegio de Michoacán, pp. 29-83.

Bourdieu, Pierre, (2007) El sentido práctico. Buenos Aires: Siglo XXI.

Braudel, Fernand, (1979) "La larga duración" en La historia y las ciencias sociales. Madrid, Alianza, pp. 60-105.

Caché von Fettweis, Yvonne y Robert Towsend Warneck, (2003) Mary Baker Eddy. Una vida consagrada a la curación cristiana. Boston, The Christian Science Pub.

Cantón, Manuela, (1998) Bautizados en fuego. Protestantes, discursos de conversión y política en Guatemala (1989-1993). Guatemala, Centro de Investigaciones Regionales de Mesoamérica y South Woodstock, Vermont: Plumsock Mesoamerican Studies.

Capps, Walter H., (1995) Religious Studies. The Making of a Discipline. Minneapolis, Fortress Press.

Carroll, Bret E., (2000) The Routledge Historical Atlas of Religion in America. Nueva York, Routledge.

Centro de Investigaciones y Estudios superiores en Antropología Social Sureste (CIESAS-Sureste), (1988-1989) Religión y sociedad en el sureste de México. 5 vols. México, CIESAS.

Corominas, Joan, (1998) Breve diccionario etimológico de la lengua castellana. Madrid, Gredos.

Csordas, Thomas J., (1997) The Sacred Self. A Cultural Phenomenology of Charismatic Healing. Los Ángeles, University of California.

Csordas, Thomas J., (2002) Body, Meaning, Healing. Boston, Palgrave.

Filocalia. Nicodemo el Hagiorita y Macario de Corinto, (1982) Volumen primero. Buenos Aires, Lumen.

Foucault, Michel, (1981) Las palabras y las cosas. México, Siglo XXI.

Foucault, Michel, (1983) La arqueología del saber. México, Siglo XXI.

Foucault, Michel, (1991) Las tecnologías del yo. Barcelona, Paidós.

Gill, Gillian, (1998) Mary Baker Eddy. Cambridge, Perseus Books.

Goldmann, Lucien, (1972) "Epistemología de la sociología” en Jean Piaget (ed.), Epistemología de las ciencias humanas. Buenos Aires, Proteo. 
Goldmann, Lucien, (1985) El hombre y lo absoluto. El Dios oculto. Barcelona, Península.

Gottschalk, Stephen, (2006) Rolling away the Stone. Mary BakerEddy's Challenge to Materialism. Indiana, University Press.

Guerra, Manuel, (2005) Diccionario enciclopédico de las sectas. Madrid, Biblioteca de Autores Cristianos.

Harrowitz, Nancy, (1989) "El modelo policíaco: Charles S. Peirce y Edgar Allan Poe" en Umberto Eco y Thomas A. Beck (eds.), El signo de los tres. Dupin, Holmes, Peirce. Barcelona, Lumen, pp. 241-263.

Heelas, Paul y Linda Woodhead, (2005) The Spiritual Revolution. Why Religion is Giving Way to Spirituality. Estados Unidos, Blackwell Pub.

Hernández M., Miguel, (2007) "El poder de la lectura en la sujeción religiosa de las voluntades" en Iztapalapa. Revistade ciencias sociales y humanidades. Año 28, números 62-63, enero-diciembre. México, Universidad Autónoma Metropolita Iztapalapa, pp. 39-68.

James, William, (1994) Las variedades de la experiencia religiosa. Barcelona, Península.

Jaspers, Karl, (1980) Origen y meta de la historia. Madrid, Alianza Universidad.

Jay, Martin, (2009) Cantos de experiencia. Variaciones modernas sobre un tema universal. Buenos Aires, Paidós.

Jonas, Hans, (2003) La religión gnóstica. El mensaje del Dios extraño y los comienzos del cristianismo. Madrid, Siruela.

Kaminer, Wendy, (2001) Durmiendo con extraterrestres. El auge del irracionalismo y los peligros de la devoción. Barcelona, Alba.

Levinas, Emmanuel, (1998) "La filosofía del hitlerismo" en Nexos. Número 245, mayo, pp. 43-49.

López-Baralt, Luce, (1999) Moradas de los corazones. Abù-lHasanal Nùrì de Bagdag. Madrid, Trotta.
Mardones, José María, (2003) La vida del símbolo. La dimensión simbólica de la religión. Bilbao, Sal Terrae.

Martuccelli, Danilo, (2007) Gramáticas del individuo. Buenos Aires, Losada.

Marty, Martin E. y R. Scott, (1991) Fundamentalisms Observed. Chicago, University of Chicago.

Marzal, Manuel M., (1986) Estudios sobre religion campesina. Perú, Pontificia Universidad Católica de Perú.

Marzal, Manuel M., (1988) Los caminos religiosos de los inmigrantes en la gran Lima. Perú, Pontificia Universidad Católica de Perú.

Marzal, Manuel M., (2002) Tierra encantada. Tratado de antropología religiosa de América Latina. Madrid, Trotta.

Melton, J. Gordon, (2003) Encyclopedia of American Religions. Estados Unidos, Gail Group.

Ortega y Gasset, José, (1976) Ideas y creencias. Madrid, Espasa Calpe.

Rudolph, Kurt, (2000) La Gnosi. Natura e storia di una religione tardoantica. Brescia, Paideia.

Segato, Rita L., (2007) La nación y sus otros. Raza, etnicidad $y$ diversidad religiosa en tiempos de política de la identidad. Buenos Aires, Prometeo.

Villoro, Luis, (2000) Creer, saber, conocer. México, Siglo XXI.

Weber, Max, (2001) "La objetividad cognoscitiva de la ciencia social y de la política social [1904]" en Ensayos sobre metodología sociológica. Buenos Aires, Amorrortu, pp. 29-101.

Weber, Max, (2002) Economía y sociedad. México, Fondo de Cultura Económica.

Yébenes, Zenia, (2008) Derrida. México, Universidad Autónoma Metropolitana. 